\title{
A Cross-Institutional Study of Instructional Characteristics and Student Outcomes: Are Quality Indicators of Online Courses Able to Predict Student Success?
}

\author{
Tanya Joosten and Rachel Cusatis \\ National Research Center for Distance Education and Technological Advancements \\ University of Wisconsin-Milwaukee
}

\begin{abstract}
A study was conducted to examine instructional characteristics of quality in online courses and their relationship to student outcomes in online courses at a National Research Center for Distance Education and Technological Advancements 2-year and a 4-year higher educational institution. Instructional characteristics included learner support, course design and organization, content design and delivery, interactivity (student-instructor and student-student), and assessment. A student survey instrument was created that captures student perceptions of the instructional characteristics of their courses, their learning, and their satisfaction with the courses. The data collected from the student survey was merged with data from institutional student information systems (e.g., demographics and course grade). This article examines the relationship between these instructional characteristics, sometimes referred to as indicators of online course quality, and their relationship to student outcomes for all students and for underrepresented students. Additional analyses were conducted to examine differences among underrepresented students (e.g., minorities, first-generation, low-income, students with impairments or disabilities) using MANOVA. Significant findings are reported.
\end{abstract}

Keywords: online, online learning, online courses, online programs, course quality, interactivity, distance education, learner support, course design, content, organization, assessment, evaluation, student success, learning, performance, student satisfaction, DETA

Joosten, T., \& Cusatis, R. (2019). A cross-institutional study of instructional characteristics and student outcomes: Are quality indicators of online courses able to predict student success? Online Learning, 23(4), 354-378. doi:10.24059/olj.v23i4.1432

\section{Author Note}

The contents of this article were developed under grant \#84.116Q, P116Q140006, from the U.S. Department of Education. However, the contents do not necessarily represent the policy of the U.S. Department of Education, and one should not assume endorsement by the federal government. 
A Cross-Institutional Study of Instructional Characteristics and Student Outcomes:

Are Quality Indicators of Online Courses Able to Predict Student Success?

\section{A Cross-Institutional Study of Instructional Characteristics and Student Outcomes: Are Quality Indicators of Online Courses Related to Student Success?}

As educational opportunities in an online environment have grown over the past several decades, institutions and instructors have developed ways to determine quality in online courses. Online courses are courses where learning is distanciated through space, or at a distance, and potentially time using various technologies, able to deliver instruction as effectively as face-toface courses, and seeing continued growth in their demand. Although inconsistent findings in regard to the efficacy of online courses in comparison to face-to-face courses have been reported, meta-analyses indicate that online courses are just as effective if not more effective when it comes to student outcomes (e.g., Allen, Bourhis, Burrell, \& Mabry, 2002; Allen, Mabry, Mattrey, Bourhis, Titsworth, \& Burrell, 2004: Means, Toyama, Murphy, Bakia, \& Jones, 2009). Not only are online courses effective, demand in online course offerings continues to grow as students require more flexibility in where and when they learn due to work, family, and other obligations. Allen and Seaman (2016) reported that "distance education enrollments continue to grow at a healthy rate, showing a 7\% increase overall between fall 2012 and fall 2014" (p. 13). With increasing demand for online courses that have shown to be just as good as face-to-face courses, research efforts continue to develop an understanding of how to best design online courses and deliver instruction online to positively influence student outcomes.

Since online learning continues to grow in higher education, there is increasing demand and need for demonstrable effective practices to ensure quality in online courses and programs and to inform practice. While many practitioners identify practices through the gathering of instructor experiences and anecdotes, researchers conduct studies to identify evidence-based practices that can be implemented by instructors (e.g., Shattuck, 2007). There is a need to not only identify practices indicative of a quality course but to also demonstrate the relationship of these practices with student outcomes. This means that the link between these instructional practices and student outcomes needs to be better understood. The best practices research tends to be narrow in that it focuses on individual pedagogical interventions, such as online discussions, rather than showing the best instructional practices as determined by online quality indicators, to positively and significantly influence student outcomes. Notably, efforts have been undertaken to increase the quality and rigor of studies in online learning and advance research in the field (see Dziuban, Picciano, Graham, \& Moskal, 2015).

There is a need for enhanced understanding as to what practices will positively influence outcomes for all students and for underrepresented students. Presently, there is a lack of research that examines student demographics (e.g., underrepresentation) and how those demographics influence student perceptions of their courses and/or the relationships of these to student outcomes. Jaggars and Bailey (2010) claim that they are unaware of any studies that examine the increase in enrollment of underrepresented students, and they note the significant barriers underrepresented students can face in enrolling and completing online courses. Johnson and Mejia (2014) reported that California community college students are $10-14 \%$ less likely to complete an online course than a traditional on-site course. Even lower rates were found in online courses among minorities (10-18\% lower) than White students. The decrease in student success was attributed to inconsistency in course quality. However, Shea and Bidjerano (2014) reported in their national study that community college students who take courses online have a significantly better chance of obtaining a degree than students who only take courses taught in a physical classroom. 
Therefore, it is important to ensure that instructional characteristics are effective in improving student outcomes for all students.

Institutionally, identifying effective, evidence-based practices to ensure the quality of courses in higher education is pertinent to meeting the needs of students, requirements of academic programs, and federal standards. How courses are structured and students' interactions within them can impact students' success in those courses (e.g., higher grades, greater learning, and higher rates of completion). Additionally, these structures and experiences can also lead to higher satisfaction in online courses and online programs, which can impact students' persistence, or continued enrollment in online courses. Despite the mode of instruction, academic programs need to provide a quality learning experience to ensure that students are fulfilling the required learning and program objectives. These objectives must meet the standards of the discipline and the labor market for which the student will obtain professional pursuits after graduation. Whether a course takes place online or on-site, the outcomes must be comparable. As Allen and Seaman (2016) reported, the majority of academic leaders through the years believe that learning outcomes in online courses are the same or superior to those in face-to-face courses. Online courses and programs continue to be a part of institutional strategy in higher education. Finally, because many times accrediting bodies of higher education institutions want to ensure the courses are being appropriately designed and supported when delivered at a distance or online, institutions need to ensure they are meeting federal regulations in delivering instruction to students. Quality of online courses and programs is paramount to institutional leaders.

\section{Review of Literature}

Institutions and instructors have worked to identify components or characteristics of successful instruction in distance education to improve the quality of course offerings provided to students and to ensure that the quality of courses offered to students at a distance or online is equal to or better than traditional classroom courses. In the early development of online courses, quality was a concern. This was, in part, due to the newness of the electronic media and associated scrutiny. Also, it may have been due to the instructional approaches used, which were mainly objectivistic and focused on knowledge transmission and summative assessment (e.g., Beare, 1989; Egan, Welch, Page, \& Sebastian, 1992) rather than active learning. Creating lectures to broadcast was a more easily acquired pedagogical skill set that mirrored instructional approaches on-site. The broadcasts of lectures may have been delivered via radio, television, videotape, or compact disc.

As a result of this electronic media scrutiny and evolving pedagogical practices, tools were developed (e.g., Quality Matters rubric, Rubric for Online Instruction) to assist instructors and institutions in guiding and evaluating their online practices (Sener, 2006) - specifically, the tools emphasized the importance of interactions, active learning, and learner support, which often were lacking in early models of distance education. Although these approaches were as good as faceto-face (e.g., Allen et al., 2002; Allen et al., 2004), over time there was a transformation in online pedagogy due to the advancement in technologies and move towards more active learning. For instance, early research indicated that courses that embrace pedagogies that can enhance the virtual classroom experience for students can lead to more positive outcomes (Picciano, 2002).

With the new mode of online instruction, most instructors lacked the pedagogical and

technological skills to take advantage of the media characteristics in online environments to create 
A Cross-Institutional Study of Instructional Characteristics and Student Outcomes: Are Quality Indicators of Online Courses Able to Predict Student Success?

more interactive learning experiences and reverted to replicating the face-to-face instruction in the online environment (Kaleta, Skibba, \& Joosten, 2009). Many of these instructors replicated the traditional classroom didactic model in the online environment or implemented correspondence models of continuing education. The focus on this didactic model of instruction placed attention on student interactions with content from reading and lecture. Teacher-centered models focused heavily on content or the idea of the "sage on the stage," where instructors focused on identifying an electronic or digital forum to deliver their lecture. A limited amount of time was spent on developing activities and materials that would help students prepare and interact in the online environment. As Fetherston (2004) discussed, there was increased acknowledgement that traditional models of learning may not be the best for learning nor the best for online learning. Moreover, few efforts were directed toward creating and incorporating student-centered activities or assessments that would provide more frequent low-stakes feedback rather than high-stakes assessments typical in a lecture model. Hence, faculty development programs were developed to better take advantage of the media and focus more on student interactions with each other and the instructor (Joosten, Barth, Harness, \& Weber, 2014). Given these limitations, the transmission model of learning offered an opportunity for improvement to the quality of instruction in online environments.

As part of the online learning transformation that occurred in higher education, researchers and theorists began to identify practices that could enhance the online experience for instructors and students based on current and past studies. These practices tended to focus on student interactions and consisted of the implementation of active learning or student-centered pedagogical models. Notably, objectivistic models of learning were becoming less prevalent, while more subjectivist or social models of learning were being developed, such as constructivism (e.g., Hung, Tan, \& Koh, 2006). Theories emerged that focused on student interactions, and researchers as well as practitioners began to enhance understandings of the importance of interactions for learning. For instance, Chickering and Gamson (1987) had already identified principles for education that focused on increasing interactivity between students and the instructor and among students themselves. They highlighted the importance of active learning and timely feedback. Yet many faculty were not implementing these practices on-site. Also, social scientists investigated computer-mediated communication to enhance online learning. Hiltz $(1988,1994)$ began exploring the effectiveness of computer-mediated communication and groups, particularly as they related to online learning. Hiltz and Meinke (1989) describe the virtual classroom as "a teaching and learning environment in a computer-mediated communication system" (p. 431) and reported increased access and improved learning in the virtual classroom through online interactions. Moreover, Moore (1989) discussed three types of interaction in distance education courses: students' interaction with content, each other, and the instructor. Later, she and Kearsley (2011) recommended that "to take advantage of [a virtual environment], instructional designers should create activities that involve interactions among each group" (p. 18). Interactions with the instructor and peers (e.g., discussions and groups) are key factors that can influence student outcomes in an online course.

Several of these explorations tended to take a systems approach to exploring interactions in online learning. A systems approach believes that there is a focus on an input-throughput-output model that will be used as a framework for this study. For instance, Moore (2009) noted that "interaction is key" (p. 79), including interaction with content, with instructors, and with classmates. Also, she noted that communication and community building should be emphasized in the course. Pedagogical models and quality measures incorporate students' interactions not only 
with content but also with each other and the instructor. The focus on a systems approach to identifying variables of interest in online learning is new since much of the early research focused on inputs and outputs rather than throughputs or student interactions. Specifically, early research focused on mode comparisons (online versus face-to-face inputs) while examining differences or comparability of output variables. Later, practice of and research on online learning transitioned to focusing on interaction, a throughput or process, as a primary indicator of quality pedagogy. Usually, these indicators are gathered through reviews of the literature and qualitative methods, such as document analysis and the gathering of faculty experiences. Several key indicators are commonly referred to when guiding instruction and course development, and evaluating course quality. These indicators are included in an array of tools to determine course quality, and each of these areas has been extensively explored, including student support (Paloff \& Pratt, 2003; Crawley, 2012; Lehman \& Conceição, 2014), design and organization (Vai \& Sosulski, 2015; Ko $\&$ Rossen, 2010), content design and delivery (Joosten, 2012; Davis, 2015; Vai \& Sosulski, 2015), interactivity (Palloff \& Pratt, 2003; Hiltz \& Goldman, 2004; Lehman \& Conceição, 2010; Joosten, 2012), and assessment (Huba \& Freed, 2000; Palloff \& Pratt, 2008; Barkley \& Major, 2015).

This study examined instructional characteristics to identify key components that positively influence student outcomes. Instructional characteristics are characteristics of course structure that influence student and instructor behaviors and student outcomes and are many times described as quality course indicators. The study included an examination of all students and then specifically analyzed those who are underrepresented. Little research examines underrepresented students in online courses and programs, which may be because of the lack of the underrepresented in online courses (see Cavanagh \& Jacquemin, 2015), yet it is important to ensure that instructional practices do not disenfranchise certain groups. The instructional characteristics components include learner support, course design and organization, interactions with instructor, interactions with peers, and assessment. The instructional characteristics instrument developed captures student perceptions of their experiences within the course to determine the course structure that influences student outcomes. By gathering students' reports of their interactions (throughput), a better understanding regarding the relationship between the course structure (input) and student outcomes (output) can be determined. Reports of student interactions can illustrate the structure influencing such attitudes and behaviors. As previously described, these components were identified as important to online course quality through a review of the literature and existing course quality tools and indicators. Through this research, the components can be identified as effective or ineffective based on their relationships to student outcomes (learning, satisfaction, and academic performance). Those components identified as effective can, in turn, be used to develop new practices to be implemented into professional development programs for online course design and instructor preparation. Instructors can utilize these practices to ensure they are providing a quality learning experience.

\section{Part 1: Instructional Characteristics and Student Outcomes for All Students}

The overarching research question in this study examined the relationship between instructional characteristics and student outcomes of online courses, according to students' perceptions: Which instructional characteristics demonstrate a significantly positive relationship with student outcomes in an online course? The hypotheses including specific variables and measures were the following:

Students' reports of instructional characteristics of online course quality, specifically learner support, design and organization, content design and delivery, interactivity with 
instructors, interactivity with peers, and assessment, will increase their perceptions of (H1a) learning, (H1b) satisfaction, and (H1c) academic performance (instructor-reported final grade retrieved from student information system [SIS] data) are positively associated with instructional characteristics, specifically (a) learner support, (b) design and organization, (c) content design and delivery, (d) interactivity with instructors, (e) interactivity with peers, and (f) assessment and evaluation. Also, as a result of exploratory factor analysis confirming a one-factor structure, (H1d) students' perceptions of instructional characteristics (full 64-item measure) will significantly increase their learning, satisfaction, and academic performance, as indicated by final grades from the SIS.

The between-group differences for underrepresented and represented students were also explored to determine if the two groups perceived the instructional characteristics differently. The research question to be tested was the following: Which instructional characteristics do underrepresented student populations perceive significantly differently than well-represented students?

\section{Part 2: Instructional Characteristics and Student Outcomes for Underrepresented Students}

Secondly, the study aimed to understand the outcomes of underrepresented students. The overarching research question explored was this: Which instructional characteristics do underrepresented student populations perceive significantly differently than their well-represented students counterparts? With such little attention to the experiences of underrepresented students in previous literature, the current study did not have any a priori hypotheses about which specific instructional characteristics would be significantly different between underrepresented students and their more privileged counterparts. However, the following hypotheses specific to underrepresented students mirrored those of the full sample:

Underrepresented students' perceptions of (H2a) learning, (H2b) satisfaction, and (H2c) academic performance (instructor-reported grade) will be increased by instructional characteristics, specifically (a) learner support, (b) design and organization, (c) content design and delivery, (d) interactivity with instructors, (e) interactivity with peers, and (f) assessment and evaluation. Also, (H2d) underrepresented students' perceptions of the instructional characteristics (full 64-item measure) will significantly increase their learning, satisfaction, and academic performance, as indicated by instructor-reported final grades.

\section{Methods}

The study incorporated a survey instrument and institutionally warehoused data. A survey instrument was developed to enhance the understanding of students' perceptions of instructional characteristics and student outcomes. The survey requested that students report on the instructional characteristics of their online courses in six areas to assess the quality of courses in the areas of learner support, design and organization, content, interactivity with instructor, interactivity with peers, and assessment. Moreover, they were asked about their learning and satisfaction. The survey consisted of demographic items and Likert items to measure students' perceptions. Additionally, data was extracted from institutionally warehoused data (SIS data), including demographic and academic performance data (i.e., grades and course completion). 
A Cross-Institutional Study of Instructional Characteristics and Student Outcomes: Are Quality Indicators of Online Courses Able to Predict Student Success?

\section{Instrumentation}

Three primary tools were investigated for the development of the instrument utilized in this study: the California State University (CSU) Chico Rubric for Online Instruction (ROI; see http://www.csuchico.edu/eoi/the_rubric.shtml), the California State Quality Online Learning and Teaching (QOLT; see http://courseredesign.csuprojects.org/wp/qualityassurance/), and the Quality Matters (QM) rubric (see https://www.qualitymatters.org/). These tools were developed over the last several decades to guide course and instructional design and the evaluation of online courses. Concepts from the tools were converted to Likert items measuring students' perceptions of the instructional characteristics or quality indicators. A similar approach was taken by RalstonBerg (2014), who developed an instrument based on items from the QM rubric and converted the items into student-centered language to gauge students' perspectives on quality. The development of these tools was based on identifying instructional characteristics of quality online courses. Expert feedback of the final instrument was gathered and incorporated.

The CSU Chico ROI was developed by a committee of faculty, administrators, staff, and students in 2003. The process included a review of the QM Rubric and other tools available at the time. The tool was a rubric with three levels of quality across six dimensions: learner support and resources, online organization and design, instructional design and delivery, assessment of student learning, innovative teaching with teaching that includes technology, and faculty use of student feedback.

According to Shattuck (2007), the QM rubric's development began in 2002 from materials produced by the faculty online training initiative based on Chickering and Ehrmann's (1996) Implementing the Seven Principles: Technology as Lever and the American Council on Education's (ACE; 1996) Guiding Principles for Distance Learning in a Learning Society to assure quality in online courses. The QM project received funding from the U.S. Department of Education Fund for the Improvement of Postsecondary Education to further develop and formalize a peer-review process for online course design and evaluation. The rubric was intended to guide reviewers and was first produced in 2004. It included eight standards: course overview and introduction, learning objectives, assessment and measurement, learning resources and materials, learner interaction, course technology, learner support, and accessibility. The QM rubric has had several iterations since its initial development.

The California State QOLT evaluation instrument was developed in 2014 after a review of literature and other tools including the CSU Chico ROI, QM rubric and program, Illinois Quality Online Course Initiative, National Survey of Student Engagement, Community of Inquiry, and Chickering and Gamson's (1987) Seven Principles of Good Practice. There are 10 dimensions included in the tool: course overview and introduction, assessment of student learning, instructional materials and resources utilized, student interaction and community, facilitation and instruction, technology for teaching and learning, learner support and resources, accessibility and universal design, course summary and wrap-up, and mobile platform readiness.

\section{Participants}

Participants $(N=501)$ were undergraduate and graduate students enrolled in a course section that was delivered online, at two Midwestern higher education institutions in the United States. Both institutions were public institutions with one being a 4-year doctorate-granting institution and the other a 2-year technical school. Data collection occurred for courses offered in spring 2016, fall 2016, spring 2017, fall 2017, and spring 2018 semesters and yielded a return rate 
on average of $9 \%$ of students emailed. Of the students who participated, $73 \%$ reported as women and $27 \%$ reported as men. Participation was solicited through an email that was sent to students enrolled in an online course. Students were asked to complete a Web-based survey.

The students included freshman (10\%), sophomores $(24 \%)$, juniors $(21 \%)$, seniors $(27 \%)$, and graduate students (19\%). Of the students who participated, the majority were full-time students $(65 \%)$ with other students reporting part-time (30\%), less than part-time (4\%), and overload (2\%). Students reported on their employment status with the majority of the students reporting working part-time (43\%). Others reported either working full-time $(33 \%)$ or other $(24 \%)$.

Underrepresented students were of interest in this study, including minorities, low-income students, first-generation students, and students with disabilities or impairments. The majority of the students responding were Caucasian or European American (63\%) with other students reporting African American (15\%), Latino (4\%), Asian (4\%), American Indian or Alaska Native (1\%), Native Hawaiian or Pacific Islander (2\%), a portion of students reported being of multiple races $(10 \%)$, and others represented by the generic group international (2\%). Minority status was determined by recoding institutionally warehoused data with nonminorities (Caucasian, European American) being the majority $(N=291,63 \%)$ and minorities being Latino, African American, Asian American, American Indian or Alaska Native, Native Hawaiian or other Pacific Islander, or other $(N=173,37 \%)$. Low-income status was determined based on recoding of Pell Grant eligibility acquired from warehoused institutional data. The majority of students were expected income $(N=237,53 \%)$ and fewer students were low income $(N=210,47 \%)$. First-generation status was determined based on the recoding of warehoused institutional data. A majority of students were not first-generation $(N=227,57 \%)$ and fewer students were first-generation $(N=$ $172,43 \%)$. A portion of students $(N=110,22 \%)$ reported a learning, sensory, or physical impairment as well.

A range of disciplines was represented in the online courses in which the responding students were enrolled, including the social sciences (39\%), professions (29\%), natural sciences (14\%), humanities (9\%), and other disciplines (10\%). The courses were lower level (67\%) and upper level and graduate-level courses (33\%).

\section{Measures for Instructional Characteristics}

Learner support. Learner support is a measure of students' perceptions of how well course materials are oriented to expectations, as well as the orientation of course policies, presence of clear directions and expectations, how accessible the instructor is, and how accessible are the course materials. Items included "The materials included activities, such as a scavenger hunt or quiz, to orient me to the course," "The instructions for the class were clear," and "Information about where to find technology assistance was provided." A total of 17 items were included in this measure with high internal consistency $(\alpha=.96)$.

Design and organization. Design and organization is a measure of students' perceptions of how well course items align with learning objectives, the types of learning objectives, and the overall organization of the course. Items included "The work was busy work," "All resources and materials were appropriately cited throughout the course," and "Course content was organized in a logical format." A total of 12 items were included in this measure with high internal consistency $(\alpha=.97)$. 
A Cross-Institutional Study of Instructional Characteristics and Student Outcomes: Are Quality Indicators of Online Courses Able to Predict Student Success?

Content. Content is a measure of students' perceptions of the materials and tools provided to them in their online course. Items included "The tools and media used were appropriate for the content being delivered," "The materials included annotations to the texts assigned," and "The materials included rich online materials, such as videos and images." A total of three items were included in this measure with high internal consistency $(\alpha=.85)$.

Interactivity with instructor. Interactivity with instructor is a measure of students' perceptions of their interactions with their instructors. Items included "I received responses to my emails in a timely manner," "The instructor helped focus online discussion on relevant issues," and "The instructor asked questions and provided new content to facilitate discussion." A total of 11 items were included in this measure with high internal consistency $(\alpha=.97)$.

Interactivity with peers. Interactivity with peers is a measure of students' perceptions of their interactions with other students. Items included "The course fostered online collaborations," "I had the opportunity to introduce myself to others," and "I participated in a group activity." A total of five items were included in this measure with high internal consistency $(\alpha=.87)$.

Assessment. Assessment is a measure of students' perceptions of how well the assessments, expectations, and grading were defined, communicated, and executed. Items included "Activities were clearly defined," "The grading policy was clearly stated," and "Clear standards were set for the instructor's posting of grades, activities, and resources." A total of 16 items were included in this measure with high internal consistency $(\alpha=.97)$.

Full instructional characteristics. Full instructional characteristics is a single measure of all items about instructional characteristics (learner support, design and organization, content, interactivity with peers, interactivity with instructors, and assessment). A total of 64 items were included in this measure with high internal consistency $(\alpha=.99)$.

\section{Measures for Student Demographics}

Disability. Disability is a student demographic that was drawn from a combination of institutionally warehoused data and student self-report in the survey. First, anyone who was identified as having a physical impairment or requiring assistance in SIS data was identified as a student with a disability. Yet this data could be underreported because students with a disability or their parents may not have reported their disability to their institution. Students were also asked a series of questions regarding ability to better determine whether they had an impairment or disability. If students responded "yes" to any one of the questions asking about physical, mental, or social disabilities, they were recognized as an individual with a disability.

First-generation status. First-generation status is a student demographic that was drawn from institutionally warehoused data. Some institutions keep records of whether or not students are first-generation. Others do not, and therefore recoding is necessary. For recoding, SIS data on parent's educational attainment was used $(1=$ middle school or less; $2=$ high school; $3=$ college or beyond). If both mother (parent 1) and father (parent 2) reported high school or less, students were identified as first-generation ( $1=$ first-generation; $0=$ not first-generation).

Minority status. Minority status was determined based on institutionally warehoused data. The measure was created by combining information from two items, one asking about ethnicity and a six-category measure of race. If students identified as Hispanic in the ethnicity measure, they received a 1 for minority status. The six-category race variable $(1=$ American Indian or Alaska Native, 2 = Asian American, 3 = African American, 4 = Native Hawaiian or Other Pacific Islander, 
$5=$ White, 6 = two or more races) was collapsed into a dichotomous measure of minority status where those who were identified as White (5) received a 0 for minority status and all other races were considered a minority and received a $1(1=$ minority, $0=$ not minority status $)$.

Low-income status. Low-income status is a student demographic that was derived from institutionally warehoused data. The dichotomous measure was created from information on students' Pell Grant eligibility. Those who were identified as eligible were considered low income, while those who were not eligible were considered not low income $(1=$ low income/Pell Grant eligible, $0=$ not low income/not Pell Grant eligible).

\section{Measures for Student Outcomes}

Learning. Learning was a combination of self-reported perceptions of knowledge that students acquired in the class and self-reported performance in the course. Items included "The class allowed me to better understand concepts," "The class helped me understand the course material," and "The class made it easy to connect ideas together." A total of 15 items were included in this measure, with higher scores indicating more learning $(\alpha=.95)$. This student-reported learning measure was an appropriate operationalization of student learning, as the measure demonstrated high internal reliability.

Satisfaction. This measure centered on students' attitude toward the course and the instructor. The measure captured several dimensions of satisfaction, including technical support, recommendation of continuing to deliver the course online, and overall effectiveness. Items included "I would recommend that the instructor continue teaching this course," "I liked the course," and "I would not recommend this course to a friend." A total of 13 items were included in this measure, with higher scores indicating more satisfaction $(\alpha=.91)$. This student-reported satisfaction measure was an appropriate operationalization of student satisfaction, as the measure demonstrates high internal reliability.

Academic performance. Institutionally warehoused final grades for each student's online course were merged with student survey reports. Final grade was operationalized as a continuous variable ranging from 1 to $12(1=\mathrm{F}, 2=\mathrm{D}-, 3=\mathrm{D}, 4=\mathrm{D}+, 5=\mathrm{C}-, 6=\mathrm{C}, 7=\mathrm{C}+, 8=\mathrm{B}-, 9=\mathrm{B}$, $10=\mathrm{B}+, 11=\mathrm{A}-, 12=\mathrm{A})$. Students who did not receive an $\mathrm{A}$ through $\mathrm{F}$ were operationalized as missing.

\section{Procedures}

Students enrolled in an online course at either institution were emailed a link to the Webbased survey administered via cloud survey software for three semesters over a 2-year span. After accessing the survey through the link, students were presented with an online informed-consent form where they could indicate consent, confirm that they were age 18 or older, and voluntarily agree to participate in the research study by clicking on a button on the bottom of the first page to enter the survey. The survey took approximately 30-45 minutes to complete. Specifically, the survey requested that students report their (a) demographic information, (b) disability or impairment assessment, (c) perceptions of instructional characteristics, (d) perceptions of student outcomes of their class, including learning and satisfaction, and (e) open-ended questions. Additional variables, including demographic (e.g., Pell Grant eligibility) and academic performance (e.g., course grade) variables were collected from the student information system and merged with the survey data. Each measure is described below, including the number of items, sample items, and reliability. 


\section{Data Analysis}

Statistical analyses included multiple regression analyses to examine the relationship between instructional characteristics and their ability to predict student outcomes in response to Hypothesis 1 (H1) for all students and Hypothesis 2 (H2) for underrepresented students. In order to address our hypotheses, hierarchical regressions were employed in order to account for the theoretical importance of instructional characteristics measures (i.e., learner support, assessment, etc.) as well as statistically establishing controls for student demographics (age, gender, academic performance [overall grade point average], ability [disability or impairment], income [low income or Pell Grant eligible], race [minority status], and postsecondary generation [first-generation]). This allowed our investigation to focus on the unique effects that student characteristics had on student outcomes. Three hierarchical regression analyses were conducted, with each containing a first regression block with the seven demographic variables and a second regression block with measures or factors of instructional characteristics depending on the research question or hypothesis. The first hierarchical multiple regression assesses the impacts on student learning, the second assesses the impacts on student satisfaction, and the third considers the impacts on student performance (final grade as derived from student information system data).

MANOVA was used to examine any differences between the vector of means in the four underrepresented groups for Research Question 1 (RQ1). MANOVAs were run with the six instructional characteristics measures serving as the dependent variables, and demographics of interest identifying underrepresented group status serving as the four separate independent variables, including ability (disability or impairment), income (low income as indicated by Pell Grant eligibility), race (minority status), and postsecondary education generation (first-generation status). These four dichotomous characteristics conceptualize the underrepresented populations of interest (students with disabilities or impairment, racial minority, low income, and first-generation students) in comparison to their traditional counterparts.

\section{Results}

\section{Part 1: Instructional Characteristics and Student Outcomes for All Students}

H1 examined the relationship between instructional characteristics and the ability to relate to student outcomes. Instructional characteristics have been shown to be indicators of the quality of course design and instructor and student behaviors that influence student outcomes in online courses. Multiple regression analyses were used to test if the instructional characteristics of learner support, design and organization, content, interactivity with instructors, interactivity with peers, and assessment significantly predicted student outcomes (learning, satisfaction, academic performance) as proposed in hypothesis one.

H1a examined the students' perceptions of instructional characteristics of their online course and perceptions of their learning. The results of the regression that indicated that the predictors explained about $81 \%$ of the variance in perceived learning $\left(R^{2}=.90, F[13,488]=\right.$ $161.12, p<.0001)$. It was found that design and organization, content, interactivity with instructor, and learner support significantly predicted learning $(\beta=.76, p<.0001, \beta=.11, p<.01$, and $\beta=$ $.23, p<.0001$, respectively); however, it was found that learner support negatively impacted student learning $(\beta=-.16, p<.05)$. The other two components, interactivity with peers $(\beta=.01, p$ $=.800)$ and assessment $(\beta=-.02, p=.767)$, did not contribute significantly to the model. 
H1b examined the students' perceptions of instructional characteristics for their online course and perceptions of their satisfaction. The results of the regression indicated the predictors explained $72 \%$ of the variance in student satisfaction $\left(R^{2}=.73, F[13,488]=98.82, p<.0001\right)$. It was found that learner support $(\beta=.26, p<.01)$ and design and organization $(\beta=.50, p<.0001)$ significantly predicted student satisfaction. The other four instructional characteristics, content $(\beta$ $=.01, p=.859)$, interactivity with instructor $(\beta=-.02, p=.777)$, interactivity with peers $(\beta=.06$, $p=.064)$, and assessment $(\beta=.07, p=.427)$, were not found to be significant.

H1c examined the students' perceptions of instructional characteristics of their online course and academic performance or students' final grades in the course. The results of the regression indicated the predictors explained about $8 \%$ of the variance $\left(R^{2}=.11, F[13,488]=\right.$ $4.39, p<.0001)$. It was found that interactivity with instructor significantly and negatively impacted final grade $(\beta=-.30, p<.01)$. The other five instructional characteristic measures learner support $(\beta=-.10, p=.528)$, design and organization $(\beta=.23, p=.093)$, content $(\beta=.17, p=.053)$, interactivity with peers $(\beta=.06, p=.337)$, and assessment $(\beta=.10, p=.508)$ did not contribute significantly to the model.

Tests to see whether the data met the assumption of collinearity indicated that multicollinearity was a concern, specifically for learner support (tolerance $=.97, \mathrm{VIF}=13.49$ ), design and organization (tolerance $=.97, \mathrm{VIF}=10.25)$, and assessment $($ tolerance $=.96, \mathrm{VIF}=$ 13.46). The three other measures did not demonstrate concern: content (tolerance $=.95, \mathrm{VIF}=$ 3.93 ), interactivity with instructor (tolerance $=.96, \mathrm{VIF}=7.15$ ), interactivity with peers (tolerance $=.96, \mathrm{VIF}=1.97)$. To address the issue of multicollinearity, rather than simply note the unreliability of the model as Field (2013) acknowledged is "the safest although unsatisfactory remedy" (p. 797), steps were taken to remedy the issue. Additional data was collected for an additional year over two semesters. Several researchers have prescribed adding more cases to reduce the collinearity (Allen, Titsworth, \& Hunt, 2009; Bowerman \& O'Connell, 1999; Field, 2013). As Allen et al. (2009) described, "because the standard error for each variable is diminished" (p. 163). Yet this did not reduce the collinearity. Next, H1d and H2d that merged the variables into one instructional characteristics measure sought to address issues of multicollinearity. Allen et al. (2009) stated, "In some cases, you might be able to combine the variables. For instance, if you have several factors from the same scale, you might be justified in treating the scale as 1-dimensional rather than multi-dimensional" (p. 163). Thus, the issue of multicollinearity was resolved. 
Table 1

Multiple Regressions for Instructional Characteristics and Student Outcomes

\begin{tabular}{|lccccccc|}
\hline & $\boldsymbol{\beta}$ & $\boldsymbol{p}$ & $\mathbf{A d j} \boldsymbol{R}^{2}$ & $\boldsymbol{R}^{2}$ & $\boldsymbol{d} \boldsymbol{f}$ & $\boldsymbol{F}$ & $\boldsymbol{p}$ \\
\hline Criterion: Learning & & & .81 & .90 & 13,488 & 161.12 & $.000^{*}$ \\
Learner support & -.16 & $.023^{*}$ & & & & & \\
Design/organization & .76 & $.000^{*}$ & & & & & \\
Content & .11 & $.004^{*}$ & & & & & \\
Interactivity (instructor) & .23 & $.000^{*}$ & & & & & \\
Interactivity (peer) & .01 & .800 & & & & & \\
Assessment & -.02 & .767 & & & & & \\
\hline Criterion: Satisfaction & & & .72 & .73 & 13,488 & 98.82 & $.000^{*}$ \\
Learner support & .26 & $.003 *$ & & & & & \\
Design/organization & .50 & $.000^{*}$ & & & & & \\
Content & .01 & .859 & & & & & \\
Interactivity (instructor) & -.02 & .777 & & & & & \\
Interactivity (peer) & .06 & .064 & & & & & \\
Assessment & .07 & .427 & & & & & \\
\hline Criterion: Performance & & & .08 & .11 & 13,488 & 4.39 & $.000^{*}$ \\
Learner support & -.10 & .528 & & & & & \\
Design/organization & .23 & .093 & & & & & \\
Content & .17 & .053 & & & & & \\
Interactivity (instructor) & -.30 & $.009 *$ & & & & & \\
Interactivity (peer) & .06 & .337 & & & & & \\
Assessment & .10 & .508 & & & & & \\
\hline
\end{tabular}

H1d examined the students' perceptions of instructional characteristics of their online course and learning, satisfaction, and academic performance or students' final grades in the course. The results of three regressions indicated that the single factor explained about $76 \%$ of the variance $\left(R^{2}=.76, F[8,493]=194.86, p<.0001\right)$ in student-reported learning $(\beta=.87, p<.0001)$. Second, the results indicated the single factor of instructional characteristics explained $70 \%$ of the variance $\left(R^{2}=.71, F[8,493]=149.64, p<.0001\right)$ in student-reported satisfaction $(\beta=.83, p<.0001)$. Third, the results indicated that the single factor of instructional characteristics explained $7 \%$ of the variance $\left(R^{2}=.08, F[8,493]=5.68, p<.0001\right)$ in final grade $(\beta=.12, p<.01)$. 
A Cross-Institutional Study of Instructional Characteristics and Student Outcomes:

Are Quality Indicators of Online Courses Able to Predict Student Success?

Table 2

Multiple Regressions for Entire Instructional Characteristic Factor and Student Outcomes

\begin{tabular}{|c|c|c|c|c|c|c|c|}
\hline & $\beta$ & $p$ & $\operatorname{Adj} R^{2}$ & $R^{2}$ & $d f$ & $F$ & $p$ \\
\hline Criterion: Learning & & & .76 & .76 & 8,493 & 194.86 & $.000^{*}$ \\
\hline $\begin{array}{l}\text { Full instructional } \\
\text { characteristics }\end{array}$ & .87 & $.000 *$ & & & & & \\
\hline Criterion: Satisfaction & & & .70 & .71 & 8,493 & 149.64 & $.000 *$ \\
\hline $\begin{array}{l}\text { Full instructional } \\
\text { characteristics }\end{array}$ & .83 & $.000^{*}$ & & & & & \\
\hline Criterion: Performance & & & .07 & .08 & 8,493 & 5.68 & $.000^{*}$ \\
\hline $\begin{array}{l}\text { Full instructional } \\
\text { characteristics }\end{array}$ & .12 & $.005^{*}$ & & & & & \\
\hline
\end{tabular}

In relation to students' perceptions of instructional characteristics, RQ1 examined whether there was a significant difference between underrepresented student populations and students who are well represented at the institutions being studied. This research question explored whether underrepresented students' perceptions of the characteristics of the instruction were different than their counterparts. A MANOVA was calculated to determine whether there were differences in perceptions of the instructional characteristics of learner support, design and organization, content, interactivity with instructor, interactivity with peers, and assessment between students who identified as or reported as underrepresented and those who reported as well represented. Representation included ability (disability or impairment), income (low income as indicated by Pell Grant eligibility), race (minority status), and postsecondary education generation (firstgeneration status). After students with missing data on any of the four underrepresented demographic characteristics were listwise deleted, the final $N$ for the MANOVA analysis was $(N$ $=365)$.

The Box $M$ test was significant at $p<.0001$. Box $\mathrm{M}=458.99, F=1.69$ (231, 11237.29), $p<.0001$, and, subsequently, the multivariate tests showed significant difference between students who reported a disability or impairment and those students who did not, Pillai's trace $=.04, F=$ $2.31(6,359), p<.05$, partial $n^{2}=.04$, first-generation and other generation, Pillai's trace $=.05, F$ $=3.25(6,359), p<.01$, partial $n^{2}=.05$, and low-income and other income students, Pillai's trace $=.04, F=2.52(6,359), p<.05$, partial $n^{2}=.04$.

Follow-up univariate tests showed that there were significant differences between two groups on three dependent variables. Students with disabilities were significantly different than students who did not report having a disability in how they perceived their content $(F[1,364]=$ $4.89, p<.05$, partial $\left.n^{2}=.01\right)$, and low-income students were significantly different than other income students in how they perceived their content $\left(F[1,364]=5.61, p<.05\right.$, partial $\left.n^{2}=.02\right)$, interactivity with instructor $\left(F[1,364]=4.89, p<.05\right.$, partial $\left.n^{2}=.01\right)$, and interactivity with peers $\left(F[1,364]=4.11, p<.05\right.$, partial $\left.n^{2}=.01\right)$.

Post hoc tests revealed that students with disabilities reported significantly lower perceptions of their content than students who did not have a disability, and low-income students reported significantly higher perceptions of content, interactivity with instructor, and interactivity 
with peers (see Figures 1, 2, 3, and 4). No significant multivariate results were found between minorities and nonminorities, and no significant univariate tests were found between firstgeneration and other generation students.

Table 3

MANOVA Results for Instructional Characteristics

\begin{tabular}{|c|c|c|c|c|c|}
\hline & Pillai's trace & $d f$ & $F$ & $p$ & Partial $n^{2}$ \\
\hline $\begin{array}{l}\text { Ability } \\
\text { (Disability/impairment or no) }\end{array}$ & .037 & 6,359 & 2.31 & .033 & .04 \\
\hline Learner support & & 1,364 & .01 & .937 & .00 \\
\hline Design/organization & & 1,364 & .634 & .427 & .00 \\
\hline Content & & 1,364 & 4.89 & $.028 *$ & .01 \\
\hline Interactivity (instructor) & & 1,364 & .752 & .387 & .00 \\
\hline Interactivity (peer) & & 1,364 & .034 & .854 & .00 \\
\hline Assessment & & 1,364 & .162 & .688 & .00 \\
\hline Generation (first or no) & .051 & 6,359 & 3.25 & .004 & .05 \\
\hline Learner support & & 1,364 & 2.553 & .111 & .01 \\
\hline Design/organization & & 1,364 & .093 & .761 & .00 \\
\hline Content & & 1,364 & .019 & .892 & .00 \\
\hline Interactivity (instructor) & & 1,364 & .368 & .544 & .00 \\
\hline Interactivity (peer) & & 1,364 & .460 & .498 & .00 \\
\hline Assessment & & 1,364 & .328 & .567 & .00 \\
\hline Race (minority or no) & .019 & 6,359 & 1.15 & .334 & .02 \\
\hline Learner support & & 1,364 & .294 & .588 & .00 \\
\hline Design/organization & & 1,364 & .253 & .616 & .00 \\
\hline Content & & 1,364 & 2.32 & .129 & .01 \\
\hline Interactivity (instructor) & & 1,364 & 1.30 & .255 & .00 \\
\hline Interactivity (peer) & & 1,364 & .078 & .781 & .00 \\
\hline Assessment & & 1,364 & .062 & .803 & .00 \\
\hline $\begin{array}{l}\text { Income (Pell Grant eligible/ } \\
\text { low income or no) }\end{array}$ & .040 & 6,359 & 2.52 & .021 & .04 \\
\hline Learner support & & 1,364 & .693 & .406 & .00 \\
\hline Design/organization & & 1,364 & 1.91 & .168 & .01 \\
\hline Content & & 1,364 & 5.61 & $.018 *$ & .02 \\
\hline Interactivity (instructor) & & 1,364 & 4.89 & $.028 *$ & .01 \\
\hline Interactivity (peer) & & 1,364 & 4.11 & $.043 *$ & .01 \\
\hline Assessment & & 1,364 & 2.07 & .152 & .01 \\
\hline
\end{tabular}


A Cross-Institutional Study of Instructional Characteristics and Student Outcomes:

Are Quality Indicators of Online Courses Able to Predict Student Success?

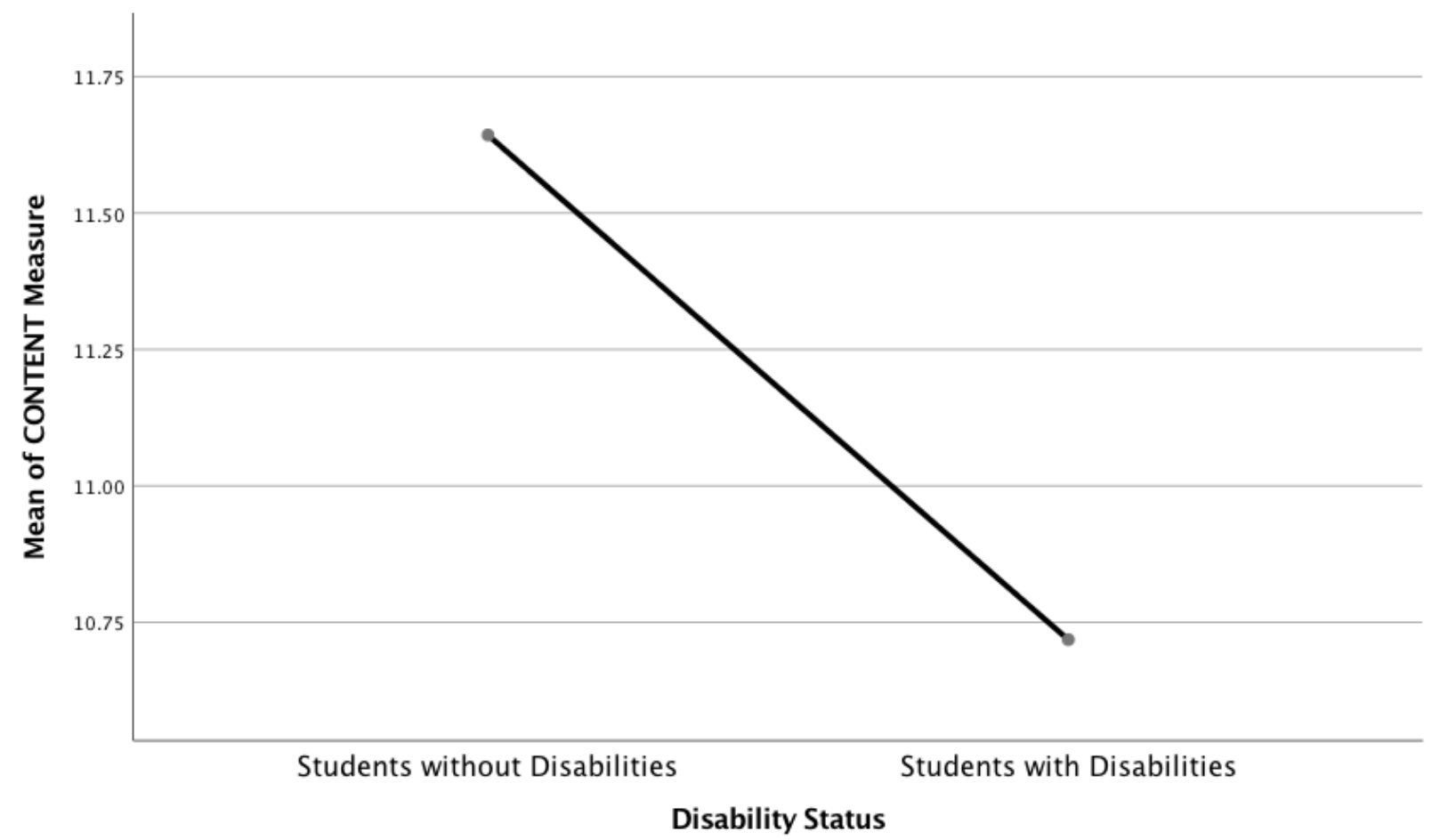

Figure 1. Means plot for content by disability status.

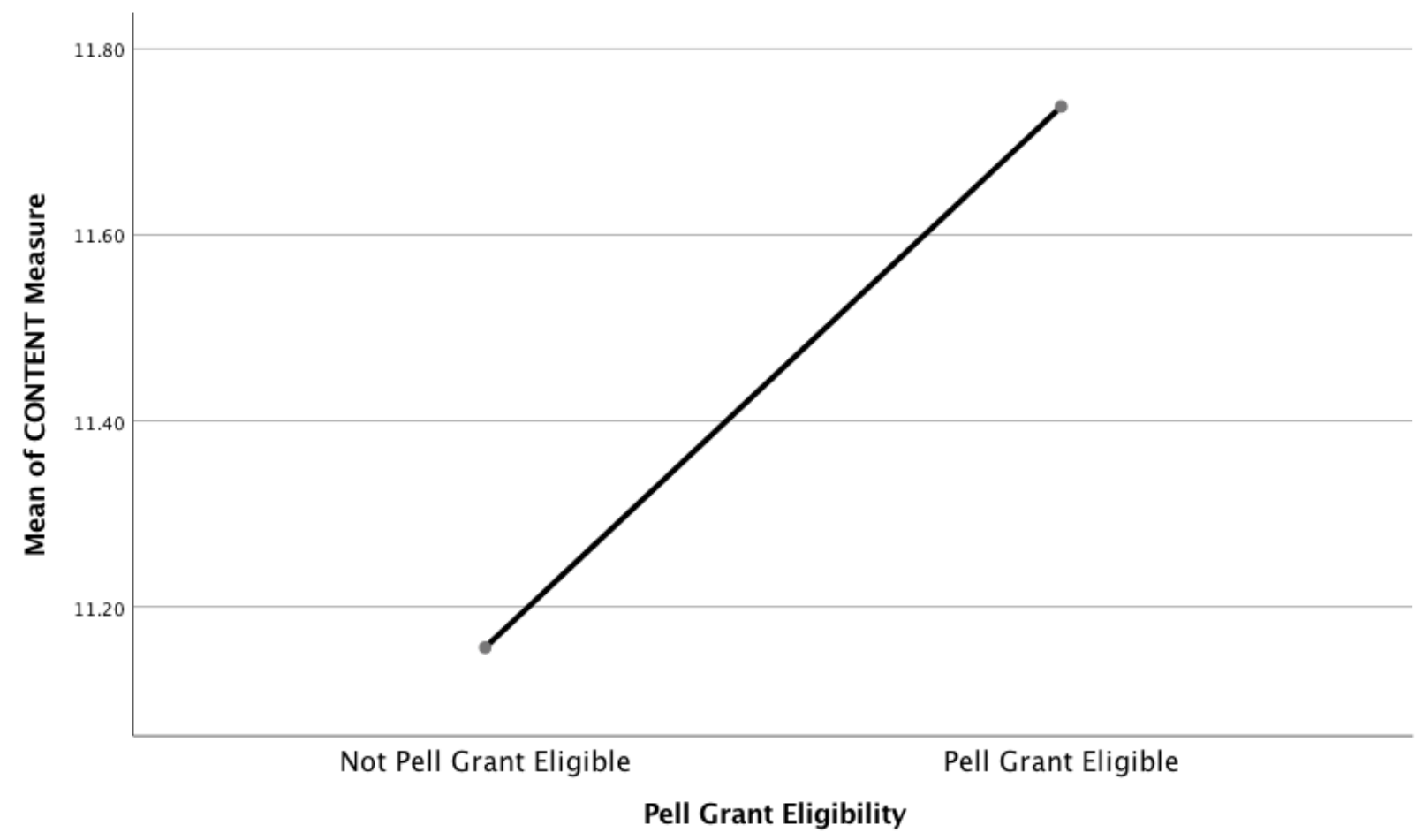

Figure 2. Means plot for content by Pell Grant eligibility. 
A Cross-Institutional Study of Instructional Characteristics and Student Outcomes:

Are Quality Indicators of Online Courses Able to Predict Student Success?

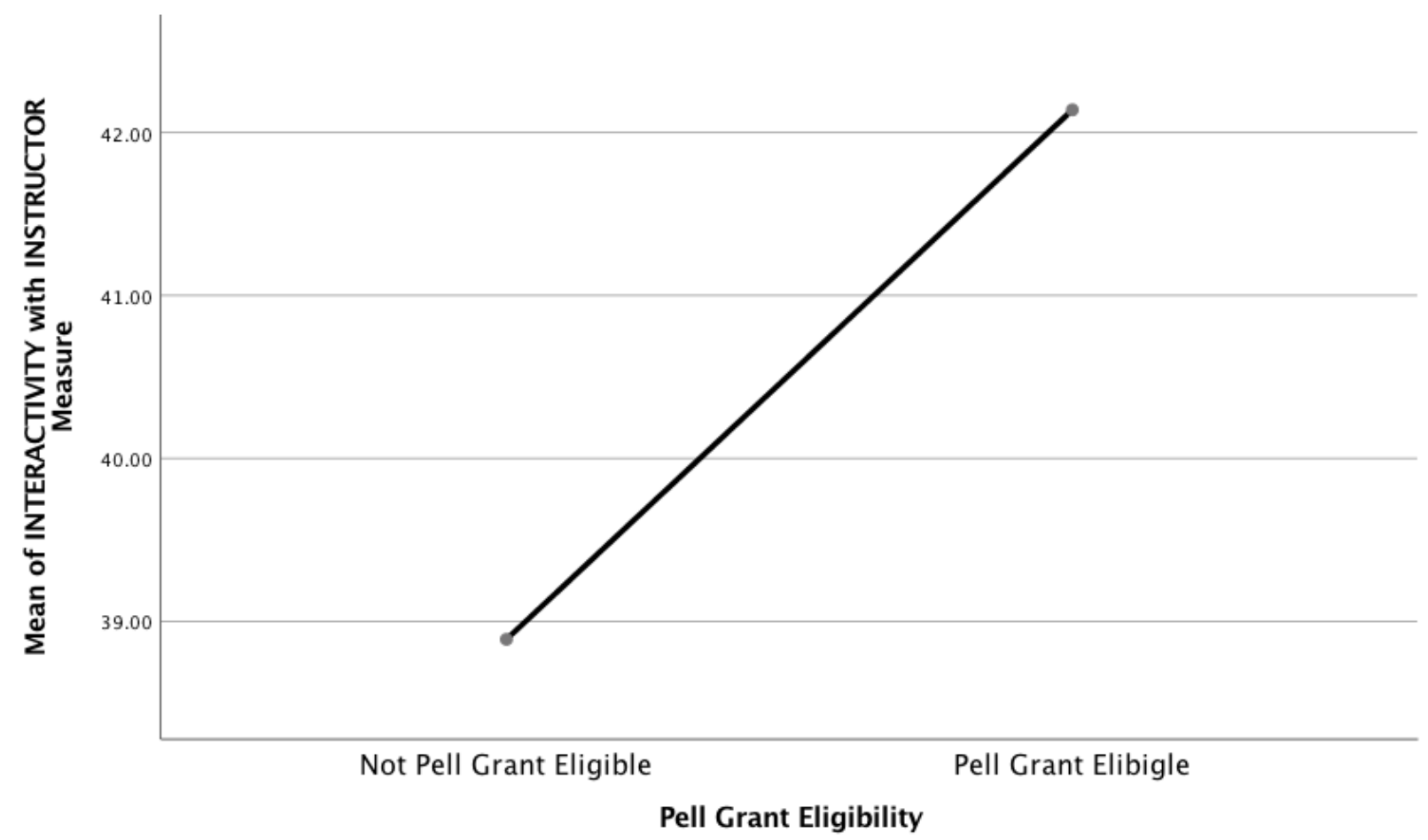

Figure 3. Means plot for interactivity with instructor by Pell Grant eligibility.

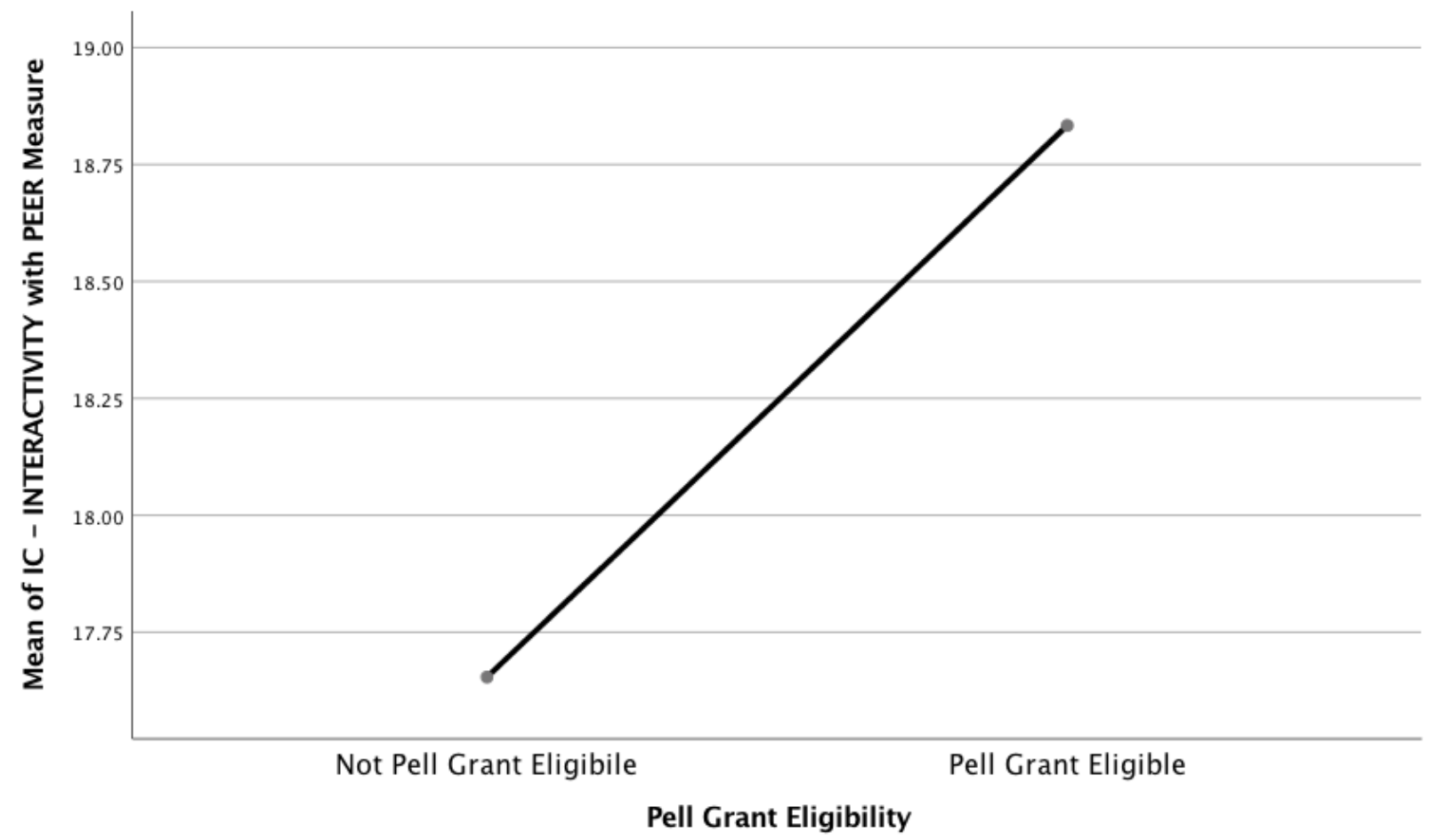

Figure 4. Means plot for interactivity with peers by Pell Grant eligibility. 
Next, to determine whether there were significant differences in the 64-item factor of instructional characteristics between students who identified as underrepresented in comparison to the traditional group, a separate MANOVA was calculated. Univariate tests indicated that none of the underrepresented groups experienced the full measure of instructional characteristics significantly differently from their more privileged counterparts: students with disability and those who do not have a disability $\left(F[1,377]=.38\right.$, partial $\left.n^{2}=.00, p=.540\right)$, first-generation students and those who are not $\left(F[1,377]=.62\right.$, partial $\left.n^{2}=.00, p=.430\right)$, minority students and nonminority students $\left(F[1,377]=.43\right.$, partial $\left.n^{2}=.00, p=.511\right)$, and Pell Grant eligible students (low income) and non-Pell Grant eligible students $\left(F[1,377]=2.77\right.$, partial $\left.n^{2}=.01, p=.097\right)$.

Table 4

MANOVA Results for Single Instructional Characteristics Factor

\begin{tabular}{|lllll|}
\hline & $d f$ & $F$ & $p$ & Partial $\boldsymbol{n}^{2}$ \\
\hline Ability (disability/impairment or no) & & & & \\
$\quad$ Full instructional characteristics & 1,377 & .38 & .540 & .00 \\
Generation (first or no) & & & & \\
$\quad$ Full instructional characteristics & 1,377 & .62 & .430 & .00 \\
$\begin{array}{l}\text { Race (minority or no) } \\
\quad \text { Full instructional characteristics }\end{array}$ & 1,377 & .43 & .511 & .00 \\
$\begin{array}{l}\text { Income (Pell Grant eligible/low income or no) } \\
\text { Full instructional characteristics }\end{array}$ & & & & \\
& 1,377 & 2.77 & .097 & .01 \\
\hline
\end{tabular}

\section{Part 2: Instructional Characteristics and Student Outcomes for Underrepresented Students}

H2 examined the relationship between students' perceptions of instructional characteristics and student outcomes, as did $\mathrm{H} 1$, yet $\mathrm{H} 2$ specifically examined underrepresented students. Here, analyses focused on a subset of the sample, those who identified as underrepresented $(n=390)$ or students who have identified as at least one of the following: minority, low income, firstgeneration, or a student with a disability. In $\mathrm{H} 2$, the multiple regression analyses were duplicated with only the underrepresented population.

$\mathrm{H} 2 \mathrm{a}$ examined the impact of instructional characteristics on students' perceptions of learning for underrepresented students. Six measures of instructional characteristics and seven demographic control measures were regressed onto learning. The results of the regression indicated the predictors explained about $80 \%$ of the variance $\left(R^{2}=.80, F[13,377]=118.80, p<\right.$ $.0001)$. It was found that design and organization $(\beta=.74, p<.0001)$, interactivity with instructors $(\beta=.26, p<.0001)$, and content $(\beta=.10, p<.05)$ significantly predicted learning. However, the other three components, learner support $(\beta=-.14, p=.104)$, interactivity with peers $(\beta=-.02, p=$ $.568)$, and assessment $(\beta=-.03, p=.744)$, did not contribute significantly to the model.

$\mathrm{H} 2 \mathrm{~b}$ examined the impact of underrepresented students' perceptions of instructional characteristics on students' satisfaction. As above, measures as above were regressed onto satisfaction. The results of the regression indicated the predictors explained about $71 \%$ of the variance $\left(R^{2}=.72, F[13,377]=73.44, p<.0001\right)$. It was found that design and organization $(\beta=$ 
$.46, p<.0001)$ and assessment $(\beta=.22, p<.05)$ significantly predicted satisfaction among underrepresented students. However, the other four components, learner support $(\beta=.16, p=$ $.123)$, content $(\beta=-.02, p=.700)$, interactivity with instructor $(\beta=-.01, p=.931)$, and interactivity with peers $(\beta=.06, p=.134)$, did not contribute significantly to the model.

$\mathrm{H} 2 \mathrm{c}$ examined the impact of underrepresented students' perceptions of instructional characteristics on students' academic performance (i.e., instructor-reported grade). Measures were regressed onto students' final grades. The results of the regression indicated the predictors explained about $7 \%$ of the variance $\left(R^{2}=.10, F[13,377]=3.32, p<.0001\right)$. It was found that content $(\beta=.21, p<.05)$ and interactivity with instructor $(\beta=-.31, p<.05)$ were included in the model, yet interactive with instructor had an inverse relationship with performance. The four characteristics, learner support $(\beta=-.14, p=.435)$, design and organization $(\beta=.27, p=.094)$, interactivity with peers $(\beta=.11 p=.129)$, and assessment $(\beta=.03, p=.874)$ did not contribute significantly to the model.

Table 5

Multiple Regressions for Instructional Characteristics and Student Outcomes for Underrepresented Students

\begin{tabular}{|lccccccc|}
\hline & $\boldsymbol{\beta}$ & $\boldsymbol{p}$ & $\mathbf{A d j} \boldsymbol{R}^{2}$ & $\boldsymbol{R}^{2}$ & $\boldsymbol{d f}$ & $\boldsymbol{F}$ & $\boldsymbol{p}$ \\
\hline Criterion: Learning & & & .80 & .80 & 13,377 & 118.80 & $.000^{*}$ \\
Learner support & -.14 & .104 & & & & & \\
Design/organization & .74 & $.000^{*}$ & & & & & \\
Content & .10 & $.025^{*}$ & & & & & \\
Interactivity (instructor) & .26 & $.000^{*}$ & & & & & \\
Interactivity (peer) & -.02 & .568 & & & & & \\
Assessment & -.03 & .744 & & & & & \\
\hline Criterion: Satisfaction & & & .71 & .72 & 13,377 & 73.44 & $.000^{*}$ \\
Learner support & .16 & .123 & & & & & \\
Design/organization & .46 & $.000^{*}$ & & & & & \\
Content & -.02 & .700 & & & & & \\
Interactivity (instructor) & -.01 & .931 & & & & & \\
Interactivity (peer) & .06 & .134 & & & & & \\
Assessment & .22 & $.037^{*}$ & & & & & \\
\hline Criterion: Performance & & & .07 & .10 & 13,377 & 3.32 & $.000^{*}$ \\
Learner support & -.14 & .435 & & & & \\
Design/organization & .27 & .094 & & & & & \\
Content & .21 & $.027^{*}$ & & & & & \\
Interactivity (instructor) & -.31 & $.018^{*}$ & & & & & \\
Interactivity (peer) & .11 & .129 & & & & & \\
Assessment & .03 & .874 & & & & & \\
\hline
\end{tabular}


$\mathrm{H} 2 \mathrm{~d}$ examined underrepresented students' overall perceptions of the instructional characteristics of their online course and learning, satisfaction, and academic performance or students' final grades in the course. The results of the first regression indicated the single factor explained about $75 \%$ of the variance $\left(R^{2}=.76, F[8,382]=150.47, p<.0001\right)$ in student-reported learning $(\beta=.87, p$ $<.0001)$. Second, the results indicated the single factor of instructional characteristics explained $70 \%$ of the variance $\left(R^{2}=.70, F[8,382]=113.67, p<.0001\right)$ in student-reported satisfaction $(\beta=.83, p<$ $.0001)$. Third, the results indicated the single factor of instructional characteristics explained $6 \%$ of the variance $\left(R^{2}=.08, F[8,382]=3.91, p<.0001\right)$ in final grade. Instructional characteristics did not predict final grade $(\beta=.12, p<.05)$.

Table 6

Multiple Regressions for Single Instructional Characteristics Factor and Student Outcomes for Underrepresented Students

\begin{tabular}{|c|c|c|c|c|c|c|c|}
\hline & $\boldsymbol{\beta}$ & $p$ & $\operatorname{Adj} R^{2}$ & $R^{2}$ & $d f$ & $F$ & $p$ \\
\hline Criterion: Learning & & & .75 & .76 & 8,382 & 150.47 & $.000^{*}$ \\
\hline $\begin{array}{l}\text { Full instructional } \\
\text { characteristics }\end{array}$ & .87 & $.000 *$ & & & & & \\
\hline Criterion: Satisfaction & & & .70 & .70 & 8,382 & 113.67 & $.000^{*}$ \\
\hline $\begin{array}{l}\text { Full instructional } \\
\text { characteristics }\end{array}$ & .83 & $.000 *$ & & & & & \\
\hline Criterion: Performance & & & .06 & .08 & 8,382 & 3.91 & $.000^{*}$ \\
\hline $\begin{array}{l}\text { Full instructional } \\
\text { characteristics }\end{array}$ & .12 & $.019 *$ & & & & & \\
\hline
\end{tabular}

\section{Discussion}

There were significant relationships with instructional predictor variables (individual constructs and the instrument in its entirety) and each criterion variable. When we examined the instructional characteristics that influenced student outcomes, we saw evidence that the entire instructional characteristic factor positively predicted student academic performance, learning, and satisfaction. Instructional characteristics of a course that are indicative of quality indicators of online course design influence student success in a course and should be of great importance in the practice of instruction in online courses. Also, there was evidence that several individual instructional characteristic components influence students' learning, satisfaction, and academic performance in online courses. The results indicate that the instrument developed from this research regarding the quality of learning in online formats predicts students' learning, satisfaction, and academic performance. The individual constructs provide more details as to what areas of course structure may be influencing student outcomes as well as implications for practice.

First, the design and organization construct was a key factor in influencing student outcomes. Design and organization positively and significantly influenced students' perceptions of learning and satisfaction as indicated in the analysis of the individual constructs of instructional characteristics. There were positive and significant relationships between design and organization with learning and satisfaction accounting for the majority of the model. Therefore, a strong effort should be made to design online courses rather than move face-to-face materials of a course into the online environment. 
A Cross-Institutional Study of Instructional Characteristics and Student Outcomes: Are Quality Indicators of Online Courses Able to Predict Student Success?

Design is the most influential measure of instructional characteristics that potentially increases student outcomes. Specifically, efforts should be made to determine the types of learning objectives, align activities with learning objectives, and organize the overall course by instructors and instructional designers. This finding reinforces previous arguments made by other researchers and practitioners of online education (e.g., Ko \& Rossen, 2010). Similar results were found for underrepresented students.

Second, learner support influenced students' perceptions of satisfaction for all students. To increase satisfaction in online courses, it is important that students be provided with an orientation to the course and associated policies. Moreover, students should be provided with clear directions and information to manage their expectations about the course and their interactions within it (e.g., how will they be graded, what the instructor's role is, and what is expected of students in activities). There also should be easy access to technology, support, and accessibility options.

Third, results indicated that student interactions with the instructor can predict student perceptions of learning. The degree to which students report instructors actively participate in their learning is important. The instructor's role is not only to design the structure of the course but connect to students and connect them to the course to enhance their learning. Moreover, the role is a complex one and the measure is of effective pedagogical practices of instructors in online courses. Thus, instructors should make an effort to show interest in student learning, maintain a productive dialogue, keep students engaged, encourage exploration of new concepts in online discussions without dominating, provide reminders and detailed feedback on assignments, and timely and effectively communicate ideas, email responses, and expectations. This finding reaffirms previous research that focused on the importance of instructors increasing their interactivity with students (e.g., Chickering \& Gamson, 1987; Moore, 2009; Moore \& Kearsley, 2011). Again, similar results were found for underrepresented students.

Fourth, content design and delivery was positively related to students' perceptions of learning for all students and to academic performance for underrepresented students. It is important here to note that content had the least statistical impact within the model. More importantly, content was not a measure of traditional methods of content delivery, such as online textbook or lectures, but a measure of pedagogically sound effective practices for online content delivery. Therefore, in designing and delivering content, effective pedagogical practices include only using short video to explain harder-tograsp concepts and processes, using annotations in the texts, and including current and rich online materials (online articles, videos). Importantly, the leanness (text) or richness (audio or video) of the media should be appropriate for the content being delivered and have enough breadth and depth for learning. These practices should be implemented by faculty and instructional designers to improve student outcomes. They are of particular importance to ensure equitable learning due to the significant and positive relationship to underrepresented students grades in the course.

Fifth, assessment was positively related to satisfaction for underrepresented students. Again, the assessment measure is based on quality measures of assessment which include managing students' expectations and providing clarity for how students will be assessed, including participation, quizzes, and exams, the alignment of assessments and activities with the course objectives and outcomes, and incorporation of an assessment approach that provides students frequent opportunities through varied forms to receive feedback on their learning. To ensure equity in their assessment planning, instructors should ensure that their expectations are clear and that they are using a student-centered, active learning approach to assessment as previously indicated in research on college assessment (see Huba \& Freed, 2000).

There were other notable findings regarding learner support and instructor interactions with students. Learner support was inversely related to students' perceptions of learning for all students but 
A Cross-Institutional Study of Instructional Characteristics and Student Outcomes: Are Quality Indicators of Online Courses Able to Predict Student Success?

not in particular for underrepresented students. Further research is needed to better understand why learner support inversely affected students' perceptions of learning and was not significant for underrepresented populations. Moreover, results indicated that student interactions with the instructor was inversely was related to academic performance for all students and similarly for underrepresented students. One could hypothesize that students who require more assistance or are struggling academically except greater communication and interactivity from their instructor. The greater their perception of instructor interactivity, the greater their perception of learning, but the lower their reported grade. Additional research is needed. The standardized beta was higher for instructor interactions for underrepresented students, which could indicate that underrepresented students rely more on those interactions than materials that provide them support.

Notably, there were significant difference between how students with disabilities perceive content in comparison to their counterparts. These differences deem further research, in particular when it comes to assuring that online education provides equal access to underprivileged students. Students with disabilities had lower perceptions of content design and delivery than their counterparts. Alternatively, low-income or Pell grant eligible students had significantly greater reports of content design and delivery, their instructor's interactivity, and interactions with their peers than their counterparts. No research has been conducted on low-income students and interactivity in their online courses, but additional research needs to be conducted to understand these differences.

In examining the instructional characteristics instrument as a whole, findings indicate the whole may be greater than the sum of its parts; predictions regarding perceived learning, satisfaction, and academic performance can be made for all students and for underrepresented students based on their overall scores on the measure, although the amount of variance accounted for by academic performance or grade was quite small. The instrument is reliable and valid. Therefore, the instrument in its entirety has greater predictability than part of the instrument measuring individual aspects of the instructional characteristics.

Some important limitations of our study should be considered. Our surveys yielded low response rates, which may incur selection bias. Students who completed the survey may be systematically different than those who did not on their perceptions of instructional characteristics and outcome measures. Furthermore, although grades are often used as an academic performance measure, there were few significant findings regarding the connection between instructional characteristics and grades in this study. Also, the course completion versus noncompletion stats did not yield a large enough sample to examine. As Moore and Kearsley (2011) noted, online courses tend to have a higher amount of success, meaning that they have higher grades and completion rates. In descriptive analysis, this was evident. There may be future considerations if this skewness is in violation of some statistical tests. Historically, student success is documented by course completion and grade, yet other outcomes rather than summative grades should be considered in future studies.

Understanding the significant relationship of individual constructs as well as the instrument in its entirety has crucial implications for practice. It is important to understand the relationships of the individual aspects of instructional characteristics due to the limitations of time and resources in designing online courses. The findings provide areas of prioritization for instructors in their design efforts, yet to truly impact student outcomes, all attributes should be considered in course design. Guiding future practice and research, the instrumentation has proven reliable and to have predictive validity. The instrumentation can be used in future studies but also can be used by practitioners to guide instructional and course design efforts to ensure quality. 
A Cross-Institutional Study of Instructional Characteristics and Student Outcomes:

Are Quality Indicators of Online Courses Able to Predict Student Success?

\section{References}

Allen, I. E., \& Seaman, J. (2016). Online report card: Tracking online education in the United States. Babson Survey Research Group.

Allen, M., Bourhis, J., Burrell, N., \& Mabry, E. (2002). Comparing student satisfaction with distance education to traditional classrooms in higher education: A meta-analysis. The American Journal of Distance Education, 16(2), 83-97.

Allen, M., Mabry, E., Mattrey, M., Bourhis, J., Titsworth, S., \& Burrell, N. (2004). Evaluating the effectiveness of distance learning: A comparison using meta-analysis. Journal of Communication, 54(3), 402-420.

Allen, M., Titsworth, S., \& Hunt, S. K. (2009). Quantitative research in communication. Thousand Oaks, CA: Sage Publications.

Barkley, E. F., \& Major, C. H. (2015). Learning assessment techniques: A handbook for college faculty. San Francisco: John Wiley \& Sons.

Beare, P. L. (1989). Media: The comparative effectiveness of videotape, audiotape, and telelecture in delivering continuing teacher education. American Journal of Distance Education, 3(2), $57-$ 66.

Bowerman, B. L., \& O’Connell, R. T. (1999). Survey planning and questionnaire design. The information system consultants handbook: Systems analysis and design. London: CRC Press.

Cavanaugh, J. K., \& Jacquemin, S. J. (2015). A large sample comparison of grade based student learning outcomes in online vs. face-to-face courses. Online Learning, 19(2), 1-8.

Chickering, A. W., \& Gamson, Z. F. (1987). Seven principles for good practice in undergraduate education. American Association of Higher Education Bulletin, 37.

Crawley, A. (2012). Supporting online students: A practical guide to planning, implementing, and evaluating services. San Francisco: John Wiley \& Sons.

Davis, T. (2015). Visual design for online learning. San Francisco: John Wiley \& Sons.

Dziuban, C. D., Picciano, A. G., Graham, C. R., \& Moskal, P. D. (2015). Conducting research in online and blended learning environments: New pedagogical frontiers. New York: Routledge.

Egan, M. W., Welch, M., Page, B., \& Sebastian, J. (1992). Learners' perceptions of instructional delivery systems: Conventional and television. American Journal of Distance Education, $6(2), 47-55$.

Fetherston, T. (2001). Pedagogical challenges for the World Wide Web. Educational Technology Review, 9(1). Retrieved from http://dl.aace.org/11556 
Field, A. (2013). Discovering statistics using IBM SPSS statistics (4th ed.). London: Sage Publications.

Hiltz, S. R. (1988, January). Collaborative learning in a virtual classroom: Highlights of findings. In Proceedings of the 1988 ACM Conference on Computer-Supported Cooperative Work (pp. 282-290). ACM.

Hiltz, S. R. (1994). The virtual classroom: Learning without limits via computer networks. Norwood, NJ: Intellect Books.

Hiltz, S. R., \& Goldman, R. (Eds.). (2004). Learning together online: Research on asynchronous learning networks. Mahwah, NJ: Routledge.

Hiltz, S. R., \& Meinke, R. (1989). Teaching sociology in a virtual classroom. Teaching Sociology, 431-446.

Huba, M., \& Freed, J. (2000). Learner-centered assessment on college campuses: Shifting the focus from teaching to learning. Needham Heights: Allyn and Bacon.

Hung, D., Tan, S. C., \& Koh, T. S. (2006). From traditional to constructivist epistemologies: A proposed theoretical framework based on activity theory for learning communities. Journal of Interactive Learning Research, 17(1), 37.

Jaggars, S. S., \& Bailey, T. (2010). Effectiveness of fully online courses for college students: Response to a Department of Education meta-analysis. Community College Research Center, Columbia University.

Johnson, H. P., \& Mejia, M. C. (2014). Online learning and student outcomes in California's community colleges. Public Policy Institute.

Joosten, T. (2012). Social media for educators. San Francisco: Wiley.

Joosten, T. (2015). Thinking systemically: A study of course communication and social processes in face-to-face and online courses (Doctoral dissertation). The University of WisconsinMilwaukee.

Joosten, T. M., Barth, D., Harness, L., \& Weber, N. L. (2014). The impact of instructional development and training for blended teaching on course effectiveness. Blended Learning: Research Perspectives, 2, 173-189.

Joosten, T., \& Reddy, D. (2015, October 1). Distance education and technological advancements research toolkit. National Research Center for Distance Education and Technological Advancements (DETA). Retrieved from http://uwm.edu/deta/toolkits/

Kaleta, R., Skibba, K., \& Joosten, T. (2007). Discovering, designing, and delivering hybrid courses. In A. G. Picciano \& C. Dzubian (Eds.), Blended learning: Research perspectives (pp. 111143). Needham, MA: Sloan Consortium. 
Ko, S., \& Rossen, S. (2010). Teaching online: A practical guide. New York: Routledge.

Lehman, R. M., \& Conceição, S. C. O. (2010). Creating a sense of presence in online teaching: How to 'be there' for distance learners. San Francisco: Jossey-Bass.

Lehman, R. M., \& Conceição, S. C. O. (2014). Motivating and retaining online students: Researchbased strategies that work. San Francisco: Jossey-Bass.

Means, B., Toyama, Y., Murphy, R., Bakia, M., \& Jones, K. (2009). Evaluation of evidence-based practices in online learning: A meta-analysis and review of online learning studies. Washington, DC: U.S. Department of Education.

Moore, M. G. (1989). Editorial: Three types of interaction. American Journal of Distance Education, $3(2), 1-7$.

Moore, J. C. (2009). A synthesis of Sloan-C effective practices. Journal of Asynchronous Learning Networks, 13(4), 73-82.

Moore, M. G., \& Kearsley, G. (2011). Distance education: A systems view of online learning. Wadsworth, CA: Cengage Learning.

Palloff, R. M., \& Pratt, K. (2003). The virtual student: A profile and guide to working with online learners. San Francisco: John Wiley \& Sons.

Palloff, R. M., \& Pratt, K. (2008). Assessing the online learner: Resources and strategies for faculty. San Francisco: John Wiley \& Sons.

Picciano, A. G. (2002). Beyond student perceptions: Issues of interaction, presence, and performance in an online course. Journal of Asynchronous Learning Networks, 6(1), 21-40.

Ralston-Berg, P. (2014). Surveying student perspectives of quality: Value of QM rubric items. Internet Learning, 3(1), 11.

Sener, J. (2006). Quality Matters: Inter-institutional quality improvement for online courses. Journal of Asynchronous Learning Networks, 10(1), 69-80.

Shattuck, K. (2007). Quality Matters: Collaborative program planning at a state level. Online Journal of Distance Learning Administration, 10(3).

Shea, P., \& Bidjerano, T. (2014). Does online learning impede degree completion? A national study of community college students. Computers \& Education, 75, 103-111.

Vai, M., \& Sosulski, K. (2015). Essentials of online course design: A standards-based guide. New York: Routledge. 